Check for updates

Cite this: RSC Adv., 2019, 9, 6011

Received 24th January 2019

Accepted 6th February 2019

DOI: $10.1039 / c 9 r a 00618 d$

rsc.li/rsc-advances

\section{Novel chalcone derivatives containing a 1,2,4- triazine moiety: design, synthesis, antibacterial and antiviral activities $\uparrow$}

\author{
Xu Tang, $\$$ Shijun Su,\$ Mei Chen, $\$$ Jun He, $\$$ Rongjiao Xia, \$ Tao Guo, $\$$ Ying Chen, \$ \\ Cheng Zhang, $\$$ Jun Wang: and Wei Xue (ID : $^{*}$
}

A series of novel chalcone derivatives containing the 1,2,4-triazine moiety were synthesized and their structures were confirmed by ${ }^{1} \mathrm{H}$ NMR, ${ }^{13} \mathrm{C}$ NMR and elemental analyses. Antiviral bioassays revealed that most of the compounds exhibited good antiviral activity against tobacco mosaic virus (TMV) at a concentration of $500 \mu \mathrm{g} \mathrm{mL}^{-1}$. The designated compound $4 \mathrm{l}$ was $50 \%$ effective in terms of curative and protective activities against TMV with 50\% effective concentrations $\left(E_{50}\right)$ of 10.9 and $79.4 \mu \mathrm{g} \mathrm{mL}^{-1}$, which were better than those of ningnanmycin $\left(81.4\right.$ and $82.2 \mu \mathrm{g} \mathrm{mL}^{-1}$ ). Microscale thermophoresis (MST) also showed that the binding of compound $4 \mathrm{l}$ to coat protein (TMV-CP) yielded a $K_{d}$ value of $0.275 \pm 0.160 \mu \mathrm{mol} \mathrm{L} L^{-1}$, which was better than that of ningnanmycin $\left(0.523 \pm 0.250 \mu \mathrm{mol} \mathrm{L}{ }^{-1}\right)$. At the same time, molecular docking studies for $4 \mathrm{l}$ with TMV-CP (PDB code:1EI7) showed that the compound was embedded well in the pocket between the two subunits of TMV-CP. Meanwhile, compound 4a demonstrated excellent antibacterial activities against Ralstonia solanacearum ( $R$. solanacearum), with an $E_{50}$ value of $0.1 \mu \mathrm{g} \mathrm{mL}{ }^{-1}$, which was better than that of thiodiazole-copper $\left(36.1 \mu \mathrm{g} \mathrm{mL}{ }^{-1}\right.$ ) and bismerthiazol $\left(49.5 \mu \mathrm{g} \mathrm{mL}^{-1}\right)$. The compounds act by causing folding and deformation of the bacterial cell membrane as observed using scanning electron microscopy (SEM). The chalcone derivatives thus synthesized could become potential alternative templates for novel antiviral and antibacterial agents.

\section{Introduction}

Plant bacterial diseases, such as citrus canker, rice bacterial leaf blight and tobacco bacterial wilt, caused by Xanthomonas axonopodis pv. citri (Xac), Xanthomonas oryzae pv. oryzae (Xoo) and Ralstonia solanacearum ( $R$. solanacearum), respectively, can be very serious and difficult to manage in agricultural production. ${ }^{\mathbf{1} 2}$ Tobacco mosaic virus (TMV), a classic pathogenic virus, has been extensively studied, and being a virus causes massive loss to crops and plants. This virus has been found to commonly infect nine plant families and at least 125 individual species including tobacco, tomato, pepper, potato, and cucumber, and its infection is extremely difficult to control under field conditions., ${ }^{3,4}$ Therefore, it is necessary to protect these crops against infestation and destruction by the bacterial and viral infections, and this has been effectively achieved

State Key Laboratory Breeding Base of Green Pesticide and Agricultural Bioengineering, Key Laboratory of Green Pesticide and Agricultural Bioengineering, Ministry of Education, Center for Research and Development of Fine Chemicals, Guizhou University, Guiyang, 550025, China. E-mail: wxue@gzu.edu.cn; Fax: +86851-88292090; Tel: +86-851-88292090

$\dagger$ Electronic supplementary information (ESI) available. See DOI: 10.1039/c9ra00618d

\$ These authors contributed to this work equally. through the use of some agrochemicals. ${ }^{5,6}$ So far, some traditional commercial viricides and bactericides, such as ribavirin, ningnanmycin, dufulin, thiodiazole-copper and bismerthiazol, are available to be used in the control of plant viral and bacterial diseases. However, the application of these traditional viricides and bactericides are limited by their negative impacts on the environment and the rapid emergence of resistance. ${ }^{7-9}$ Thus, exploring novel lead compounds with potent agricultural bioactivities is very crucial in the agricultural chemistry. ${ }^{\mathbf{1 0}}$

Recent works have emphasized that the skeleton of chalcones has structural characteristics typical of diaryl enone scaffold, and are an important class of natural and synthetic bioactive compounds, which exhibit a broad spectrum of pharmacological activities, ${ }^{\mathbf{1 1 - 1 5}}$ including antifungal, ${ }^{\mathbf{1 6}}$ antibacterial, ${ }^{17}$ antiviral, ${ }^{18}$ inhibitors, ${ }^{19}$ anticancer, ${ }^{20}$ antiparasitic, ${ }^{21}$ anti-Alzheimer's disease, ${ }^{22}$ antitrichomonal, ${ }^{23}$ anti-trypanosoma cruzi $^{24}$ activities. Meanwhile, Verma et al. demonstrated that a series of chalcones derivatives could be used to control plant viruses. $^{25}$ In our previous study, we had demonstrated the synthesis of a series of (E)-3-(3,4-dimethoxyphenyl)-1-(4-(2(quinazolin-4-ylthio)ethoxy)phenyl)prop-2-en-1-one and $(E)-3-$ (4-(2-(4-((E)-3-(4-fluorophenyl) acryloyl) phenoxy)ethoxy)-3methoxy phenyl)acrylic acid derivatives (Fig. 1 1a, 1b), which exhibited excellent antiviral activities. ${ }^{26,27}$ 

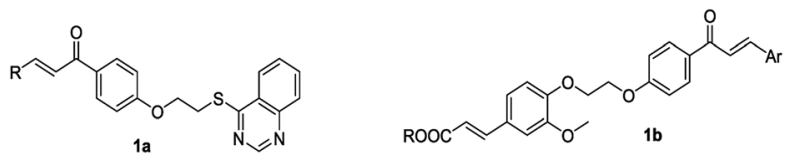

Fig. 1 Compounds previously reported against tobacco mosaic virus (TMV).

1,2,4-triazine and their derivatives are an important class of heterocyclic compounds and thus have been reported in a wide spectrum of biological activities, ${ }^{28-31}$ including antithrombotic, ${ }^{32}$ anti-oxidant, ${ }^{33}$ anticancer, ${ }^{34}$ antiplatelet, ${ }^{35}$ thromboxane synthetase inhibition, ${ }^{36}$ anti-inflammatory, ${ }^{37}$ antimalarial $^{38}$ and $\alpha$-glucosidase inhibition. ${ }^{39}$ It has also been reported that a minor modification in the structure of 1,2,4triazine can lead to quantitative, as well as qualitative changes in the biological activities. ${ }^{40}$ Fu et al. reported potent inhibitory effect of 1,2,4-triazine and their derivatives against three cell lines (MGC-803, EC-109 and PC-3) compared to 5-fluorouracil. ${ }^{34}$ However, there are only few studies that focus on 1,2,4-triazine moiety to be potentially utilize them as an antibacterial and antiviral scaffold. Based on these, it is of urgent importance to search for novel effective agro-chemicals that have unique mechanism of action. In this work, 5,6-disubstituted-1,2,4triazine group was introduced into the 4-position of chalcone nucleus to build a new molecular structure and the potency of which was tested in terms of biological activity (Fig. 2). The synthesized compounds were evaluated for their antibacterial and antiviral activities.

\section{Experimental}

\subsection{Methods and materials}

Melting points of the synthesized compounds $(\mathbf{4 a}-\mathbf{4 w})$ were measured using XT-4 Binocular Microscope (Beijing Tech. Instrument, China) and were uncorrected. Using DMSO- $d_{6}$ as the solvent and TMS as an internal standard ${ }^{1} \mathrm{H}$ and ${ }^{13} \mathrm{C}$ NMR spectra of the target compounds were recorded using JEOL-ECX 500 NMR spectrometer (JEOL, Japan). HRMS data were obtained using Thermo Scientific Q Exactive Hybrid Quadrupole Mass

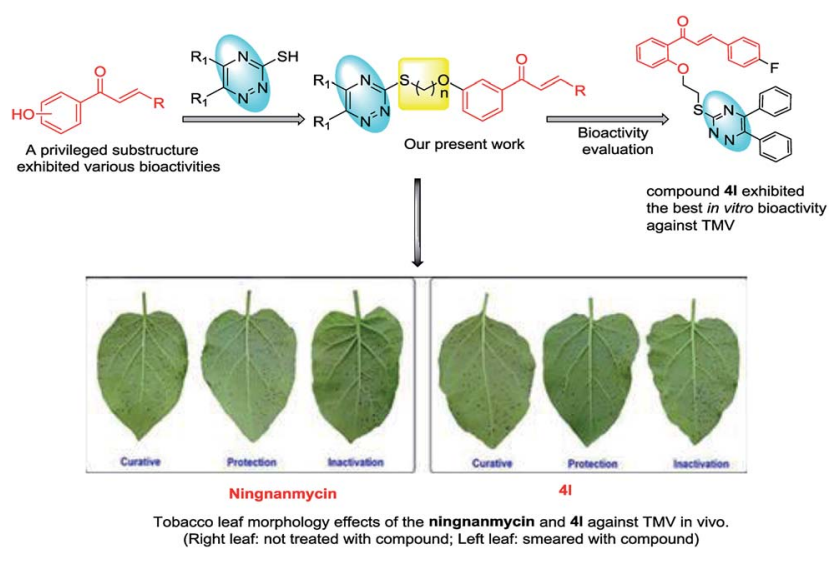

Fig. 2 Design route of the title compounds $4 a-4 w$.
Spectrometer (Thermo Scientific Inc., St Louis, MO, USA). The microscale thermophoresis (MST) of the compounds to check the interaction with TMV CP (tobacco mosaic virus coat protein) was determined using a micro thermophoresis instrument (NanoTemper Technologies GmbH, Germany). The fluorescence spectroscopy of the compounds interacting with TMV CP was determined by FluoroMax-4 fluorescence spectrometer (HORIBA Scientific, France). The molecular docking was performed by using DS-CDocker implemented in Discovery Studio (version 4.5). All reagents and solvents were purchased from Chinese Chemical Reagent Company and were of chemically pure analytical grade reagents. The synthetic route to chalcone derivatives containing 1,2,4-triazine moiety is shown in Scheme 1. The intermediates $\mathbf{1}, \mathbf{2}$ and $\mathbf{3}$ were prepared according to the methods already reported in the literature..$^{26,27,41}$

\subsection{General procedure for the synthesis of intermediates 1 and 2}

As shown in Scheme 1, using 1-(4-hydroxyphenyl) ethan-1-one or 1-(2-hydroxyphenyl)ethan-1-one and different substituted benzaldehyde as the initial materials in ethanol under ice-bath conditions in the presence of different substituted chalcone, intermediate 2 was favourably prepared according to the previously reported procedure. ${ }^{26,27}$ The ${ }^{1} \mathrm{H}$ NMR, ${ }^{13} \mathrm{C}$ NMR and HMRS spectra of the intermediate 2 have been provided in the ESI. $\dagger$

\subsection{General procedure for the synthesis of intermediate 3}

A general synthesis of 5,6-diphenyl-1,2,4-triazine-3-thiol or 5,6dimethyl-1,2,4-triazine-3-thiol is shown in Scheme 1. Benzil (10 $\mathrm{mmol}$ ) or biacetyl $(10 \mathrm{mmol})$ with thio-semicarbazide $(11 \mathrm{mmol})$ was refluxed in acetic acid $(20 \mathrm{~mL})$ and water $(35 \mathrm{~mL})$, to obtain the corresponding 5,6-diphenyl-1,2,4-triazine-3-thiol or 5,6dimethyl-1,2,4-triazine-3-thiol (3). ${ }^{41}$

\subsection{General procedure for the synthesis of title compounds} 4a-4w

The synthetic route to the title compounds, $(E)-1-(4-(2-((5,6-$ diphenyl-1,2,4-triazin-3-yl)thio)ethoxy)phenyl)-3-(2-substituted aromatic groups)prop-2-en-1-one or $(E)-1$-(2-(2-((5,6-diphenyl1,2,4-triazin-3-yl)thio)ethoxy)phenyl)-3-(2-substituted aromatic groups)prop-2-en-1-one derivatives $(\mathbf{4 a - 4 w )}$ are shown in Scheme 1. A mixture of intermediate $3(10 \mathrm{mmol})$ and anhydrous potassium carbonate $(30 \mathrm{mmol})$ in dimethylformamide (DMF, $40 \mathrm{~mL}$ ) was stirred at room temperature for $1 \mathrm{~h}$. Then, the intermediate $2(12 \mathrm{mmol})$ was added to the above solution and stirred at room temperature for 6-8 h. Upon completion of reaction (indicated by TLC), the mixture was extracted, the solvent was removed under vacuum, and the crude product was then separated by column chromatography with petroleum ether/ethyl acetate $(3: 1 \mathrm{v} / \mathrm{v})$ to obtain the designated title compounds $4 \mathbf{4}-\mathbf{4 w}$ at different yields. The ${ }^{1} \mathrm{H}$ NMR, ${ }^{13} \mathrm{C}$ NMR and HMRS spectra of the designated title compounds $\mathbf{4 a - 4 w}$ are also provided in the ESI. $\dagger$ 


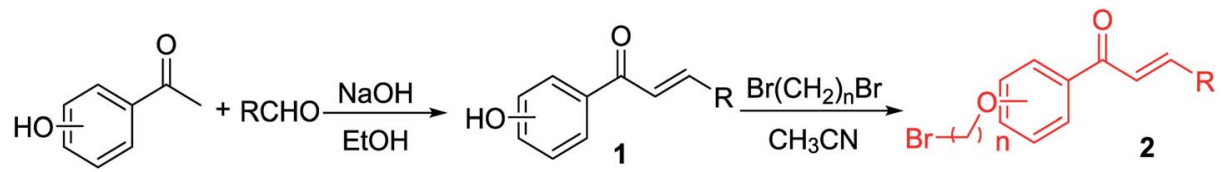<smiles>[R]C/C=C/C(=O)c1ccc(CSc2nnc([R])c([R])n2)cc1</smiles>

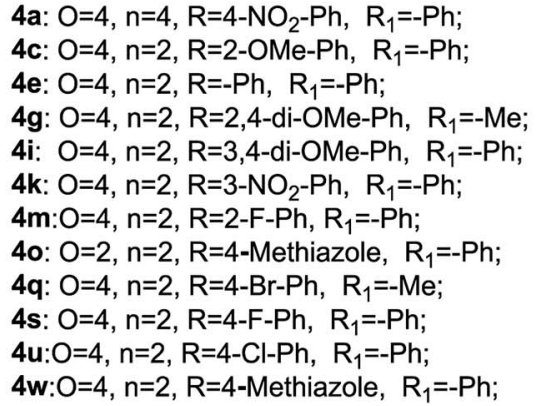

4b: $\mathrm{O}=2, \mathrm{n}=2, \mathrm{R}=2-\mathrm{OMe}-\mathrm{Ph}, \mathrm{R}_{1}=-\mathrm{Ph}$

4d: $\mathrm{O}=4, \mathrm{n}=2, \mathrm{R}=2,4$-di-OMe-Ph, $\mathrm{R}_{1}=-\mathrm{Ph}$

4f: $O=4, n=2, R=2$-furan, $R_{1}=-P h$

4h: $\mathrm{O}=4, \mathrm{n}=2, \mathrm{R}=2-\mathrm{Cl}-\mathrm{Ph}, \mathrm{R}_{1}=-\mathrm{Ph}$

4j: $O=4, n=2, R=4-O M e-P h, R_{1}=-P h$

4I: $\mathrm{O}=2, \mathrm{n}=2, \mathrm{R}=4-\mathrm{F}-\mathrm{Ph}, \mathrm{R}_{1}=-\mathrm{Ph}$

4n: $\mathrm{O}=2, \mathrm{n}=2, \mathrm{R}=\mathrm{N}, \mathrm{N}-$ di-Me-Ph, $\mathrm{R}_{1}=-\mathrm{Ph}$

4p: $O=2, n=2, R=3-M e-P h, R_{1}=-P h$

4r: $\mathrm{O}=4, \mathrm{n}=2, \mathrm{R}=4-\mathrm{t}-\mathrm{Bu}-\mathrm{Ph}, \mathrm{R}_{1}=-\mathrm{Ph}$

4t: $O=2, n=2, R=2$-thiophene, $R_{1}=-P h$

4v: $\mathrm{O}=4, \mathrm{n}=3, \mathrm{R}=4-\mathrm{Cl}-\mathrm{Ph}, \mathrm{R}_{1}=-\mathrm{Ph}$

Scheme 1 Synthetic route to title compounds $4 a-4 w$.

\section{Results and discussion}

\subsection{Spectral properties}

${ }^{1} \mathrm{H}$ NMR, ${ }^{13} \mathrm{C}$ NMR and HRMS spectra of the target compounds are provided in the ESI. $\dagger$ In ${ }^{1} \mathrm{H}$ NMR spectra, multiplet signals at $\delta 8.71-6.33 \mathrm{ppm}$ indicate the presence of protons in olefinic bonds and aromatic nuclei, and a singlet at $\delta 4.59-4.20 \mathrm{ppm}$ and 3.80-3.40 ppm reveals the presence of $-\mathrm{OCH}_{2}-$ and $-\mathrm{SCH}_{2}-$ groups, respectively. The absorption signals at $\delta$ 192.94-187.20 in ${ }^{13} \mathrm{C}$ NMR spectra confirm the presence of $-\mathrm{C}=\mathrm{O}$ group, while the absorption signals at $\delta 67.99-55.53$ and $55.52-29.31 \mathrm{ppm}$ in ${ }^{13} \mathrm{C}$ NMR spectra confirm the presence of $-\mathrm{OCH}_{2}-$ and $-\mathrm{SCH}_{2}-$ groups, respectively. In the HRMS spectra of the title compounds, the characteristic absorption signals of $[\mathrm{M}+\mathrm{H}]^{+}$ ions were obtained, which agree with their molecular weights.

\subsection{Antiviral activity of the title compounds against TMV}

Using $N$. tabacun L. leaves under the same age as that of test subjects, the curative, protective and inactivation activities against TMV (in vivo) at a concentration of $500 \mu \mathrm{g} \mathrm{mL} \mathrm{m}^{-1}$ were evaluated by the half-leaf blight spot method ${ }^{9,26,27,42}$ and the obtained results are shown in Table 1 . The preliminary bioassay results demonstrated that the inhibitory rates of title compounds (4a-4w) against TMV ranged from 30.6 to $65.6 \%$ in terms of their curative activities, while their protective and inactivation activities ranged from 34.3 to $62.7 \%$ and 23.3 to $86.8 \%$, respectively. Among them, the designated compounds, $\mathbf{4 g}, 4 \mathbf{j}, \mathbf{4 k}, \mathbf{4 l}, \mathbf{4 0}, \mathbf{4 u}$ and $\mathbf{4 w}$ afforded better curative activities against TMV at $500 \mu \mathrm{g} \mathrm{mL} \mathrm{m}^{-1}$, with $54.9 \%, 57.1 \%, 55.3 \%, 62.7 \%$, $61.4,65.6 \%$ and $60.6 \%$, respectively. These compounds were found to exhibit better antiviral activities than ningnanmycin
(45.7\%). In addition, $\mathbf{4 b}, \mathbf{4 g}, \mathbf{4 k}, \mathbf{4 l}, \mathbf{4 u}$ and $\mathbf{4 v}$ compounds exhibited significant protective activities against TMV at $500 \mu \mathrm{g}$ $\mathrm{mL}^{-1}$, with $58.7 \%, 55.5 \%, 56.8 \%, 58.6 \%, 62.7 \%$ and $56.2 \%$, respectively, which were even better than that of ningnanmycin (53.4\%). The inactivation activity of the compound $4 \mathbf{k}$ at $500 \mu \mathrm{g}$ $\mathrm{mL}^{-1}$ was $86.8 \%$, which was also better than that of ningnanmycin $(77.3 \%)$.

To compare the antiviral activity of the synthesized compounds $(\mathbf{4 a}-\mathbf{4 w}), \mathrm{EC}_{50}$ values of $4 \mathrm{~g}, 4 \mathbf{k}, \mathbf{4 l}$ and $4 \mathbf{u}$ were calculated and have been summarized in Table 2. It could be seen that compounds $\mathbf{4 g}, \mathbf{4 k}, \mathbf{4 l}$ and $\mathbf{4 u}$ exhibited higher curative activity than ningnanmycin $\left(81.5 \mu \mathrm{g} \mathrm{mL} \mathrm{mL}^{-1}\right)$, with $\mathrm{EC}_{50}$ values of 17.5, 21.8, 10.9 and $72.2 \mu \mathrm{g} \mathrm{mL} \mathrm{m}^{-1}$, respectively. Compounds $4 \mathrm{l}$ and $\mathbf{4 u}$ exhibited the best protective activity against TMV, with $\mathrm{EC}_{50}$ values of 79.4 and $52.4 \mu \mathrm{g} \mathrm{mL}{ }^{-1}$, respectively, which were better than that of ningnanmycin $\left(82.3 \mu \mathrm{g} \mathrm{mL} \mathrm{m}^{-1}\right)$. Notably, compound $4 \mathbf{k}$ was found to exhibit significant inactivation activity $\left(2.5 \mu \mathrm{g} \mathrm{mL} \mathrm{m}^{-1}\right)$, which was similar to ningnanmycin (1.1 $\left.\mu \mathrm{g} \mathrm{mL}^{-1}\right)$. It can be implied from these results that most of these novel chalcone derivatives containing 1,2,4-triazine moiety could be further studied as a potential alternative template in the search for novel antiviral agents.

\subsection{Structure-activity relationship (SAR) of the title compounds against TMV}

An analysis of Tables 1 and 2 reveals that variations in the structural features of chalcone derivatives containing 1,2,4triazine moiety could play a role in their anti-TMV activities. First, the 4-F-Ph, 4-methylthiazole and 4-Cl-Ph groups at $-\mathrm{R}$ position greatly improved the curative activities of the title compounds against TMV. For instance, the curative activities of the target compounds $4 \mathrm{l}(\mathrm{R}=4$ - $\mathrm{F}-\mathrm{Ph}), 4 \mathbf{u}(\mathrm{R}=4$-Cl-Ph) and $4 \mathbf{o}(\mathrm{R}$ 
Table 1 Antiviral activities of the target compounds against TMV in vivo at $500 \mu \mathrm{gL}^{-1}$

\begin{tabular}{|c|c|c|c|}
\hline Compd. & Curative activity $^{a}(\%)$ & Protective activity $^{a}(\%)$ & Inactivation activity $^{a}(\%)$ \\
\hline $4 a$ & $49.4 \pm 0.8$ & $46.3 \pm 7.9$ & $60.9 \pm 2.4$ \\
\hline $4 \mathbf{b}$ & $40.4 \pm 0.8$ & $58.7 \pm 1.3$ & $43.8 \pm 4.2$ \\
\hline 4d & $48.3 \pm 1.3$ & $44.6 \pm 4.4$ & $55.2 \pm 1.8$ \\
\hline $4 e$ & $56.4 \pm 1.0$ & $41.7 \pm 4.6$ & $46.3 \pm 0.1$ \\
\hline 4f & $55.6 \pm 2.3$ & $38.7 \pm 2.4$ & $50.8 \pm 1.9$ \\
\hline $4 \mathbf{i}$ & $54.9 \pm 9.7$ & $42.2 \pm 0.5$ & $52.1 \pm 2.5$ \\
\hline $4 j$ & $57.1 \pm 1.1$ & $51.7 \pm 0.1$ & $62.9 \pm 0.3$ \\
\hline $4 \mathbf{k}$ & $55.3 \pm 0.6$ & $56.8 \pm 0.9$ & $86.8 \pm 1.0$ \\
\hline 41 & $62.7 \pm 0.3$ & $58.6 \pm 1.3$ & $62.6 \pm 2.0$ \\
\hline $4 \mathrm{~m}$ & $45.2 \pm 4.3$ & $39.5 \pm 3.2$ & $51.1 \pm 1.1$ \\
\hline $4 n$ & $44.1 \pm 1.2$ & $51.1 \pm 0.3$ & $23.9 \pm 9.2$ \\
\hline $4 s$ & $43.1 \pm 0.5$ & $27.3 \pm 1.0$ & $51.2 \pm 2.2$ \\
\hline $4 t$ & $56.1 \pm 0.4$ & $51.3 \pm 1.9$ & $46.2 \pm 7.6$ \\
\hline $4 u$ & $65.6 \pm 0.1$ & $62.7 \pm 0.7$ & $51.6 \pm 0.7$ \\
\hline $4 v$ & $50.7 \pm 1.8$ & $56.2 \pm 2.3$ & $38.8 \pm 2.6$ \\
\hline $4 w$ & $60.6 \pm 0.5$ & $50.8 \pm 0.1$ & $49.6 \pm 0.9$ \\
\hline Ningnanmycin $^{b}$ & $45.7 \pm 2.6$ & $53.4 \pm 2.4$ & $77.3 \pm 1.6$ \\
\hline
\end{tabular}

${ }^{a}$ Average of three replicates. ${ }^{b}$ A commercial agricultural antiviral agent ningnanmycin was used for comparison of antiviral activities.

$=4$-methylthiazole) were $62.7 \%, 65.6 \%$ and $61.4 \%$, respectively, which were better than that of other substituent groups. In addition, when -R was 2-O-Me-Ph, 2,4-di-OMe-Ph, 3- $\mathrm{NO}_{2}-\mathrm{Ph}, 4$ $\mathrm{F}-\mathrm{Ph}$, 4-methylthiazole and 4-Cl-Ph groups, the protective activities of the corresponding compounds $\mathbf{4 b}, \mathbf{4 g}, \mathbf{4 k}, \mathbf{4 l}, \mathbf{4 o}, \mathbf{4 u}$

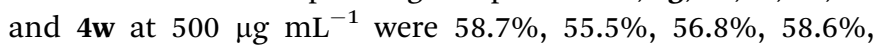
$55.9 \%, 62.7 \%$ and $56.2 \%$, respectively, which were better than that of ningnanmycin (53.4\%). Furthermore, when -R was 3$\mathrm{NO}_{2}-\mathrm{Ph}$ group, the inactivation activity of the compound $4 \mathbf{k}$ at $500 \mu \mathrm{g} \mathrm{mL} \mathrm{m}^{-1}$ was $86.8 \%$, which was better than that of ningnanmycin $(77.3 \%)$. Second, when $\mathrm{R}_{1}$ was substituted by a $\mathrm{CH}_{3}$ group, the corresponding compound $\mathbf{4 g}\left(\mathrm{R}_{1}=\mathrm{Me}, \mathrm{R}=3,4\right.$ di-OMe) had better curative, protection and inactivation effect against TMV than the compound bearing a $-\mathrm{Ph}$ (4c) group. When $\mathrm{R}$ was substituted with a 3,4-di-OMe-Ph, 3- $\mathrm{NO}_{2}-\mathrm{Ph}, 4-\mathrm{F}-\mathrm{Ph}$ or 4-Cl-Ph group, the obtained compounds exhibited better curative, protection and inactivation activities against TMV. For instance, the curative, protection and inactivation effects of the target compounds $\mathbf{4 g}\left(\mathrm{R}=3,4\right.$-di-OMe-Ph, $\left.\mathrm{R}_{1}=-\mathrm{Me}\right)$, $4 \mathbf{k}\left(3-\mathrm{NO}_{2}\right.$ $\left.\mathrm{Ph}, \mathrm{R}_{1}=-\mathrm{Ph}\right), \mathbf{l l}\left(4-\mathrm{F}-\mathrm{Ph}, \mathrm{R}_{1}=-\mathrm{Ph}\right)$ and $\mathbf{4 u}\left(4-\mathrm{Cl}-\mathrm{Ph}, \mathrm{R}_{1}=-\mathrm{Ph}\right)$

Table $2 \mathrm{EC}_{50}$ values of the $4 \mathrm{~g}, 4 \mathrm{k}, 4 \mathrm{l}$ and $4 \mathrm{u}$ against TMV in vivo ${ }^{a}$

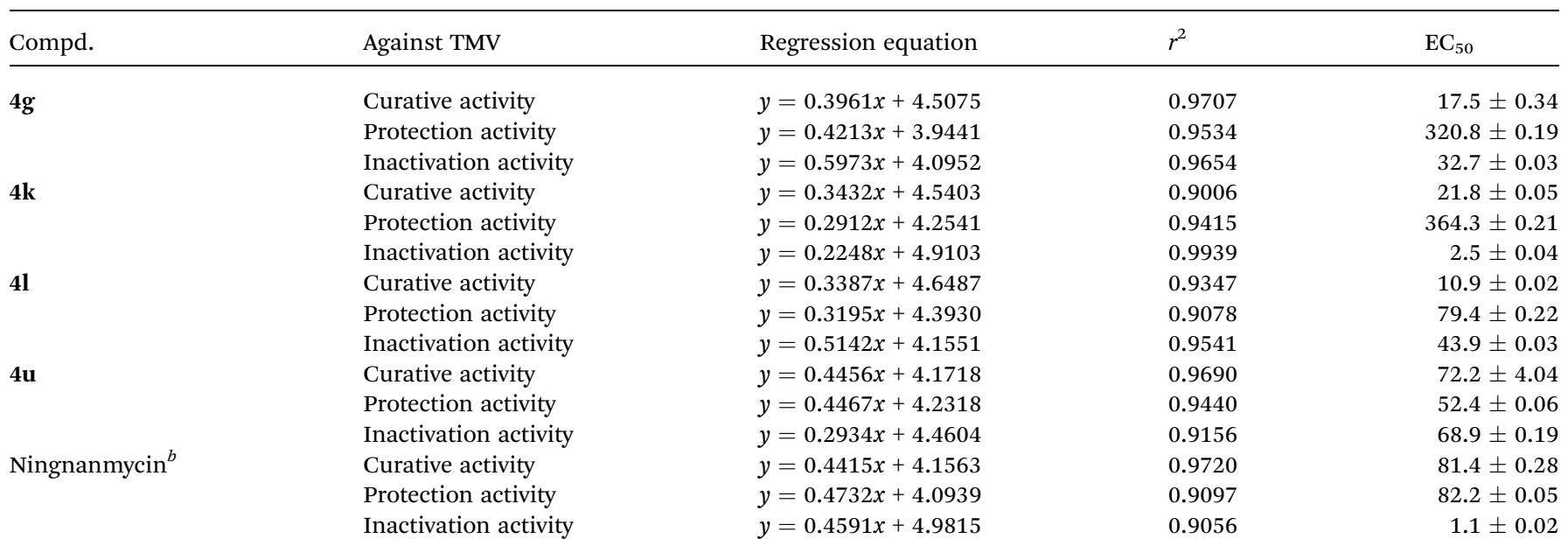

${ }^{a}$ Average of three replicates. ${ }^{b}$ A commercial agricultural antiviral agent ningnanmycin was used for comparison of antiviral activities. 
were $54.9 \%, 55.5 \%$ and $64.6 \%, 55.3 \%, 56.8 \%$ and $86.8 \%, 62.7 \%$, $58.6 \%$ and $62.6 \%, 65.6 \%, 62.7 \%$ and $51.6 \%$, respectively, which were better than that of ningnanmycin $(45.7 \%, 53.4 \%$ and 77.3\%) (Fig. 3).

\subsection{Binding sites of 4l, 4d, 40 and ningnanmycin to TMV-CP}

To further analyze the interactions between the title compounds and TMV coat protein (TMV CP), the microscale thermophoresis (MST) analysis was used. ${ }^{43}$ The MST results as summarized in Fig. 4 and Table 3 show that the binding of compounds $4 \mathbf{l}, \mathbf{4 d}$, 4o and ningnanmycin to TMV CP protein yielded $K_{\mathrm{d}}$ values of $0.275 \pm 0.160 \mu \mathrm{mol} \mathrm{L}{ }^{-1}, 81.744 \pm 22.310 \mu \mathrm{mol} \mathrm{L}^{-1}, 245.285 \pm$ $63.860 \mu \mathrm{mol} \mathrm{L}^{-1}$ and $0.523 \pm 0.250 \mu \mathrm{mol} \mathrm{L}{ }^{-1}$, respectively. As indicated in MST, $\mathbf{4 l}$ and ningnanmycin share strong affinity, while 4d shares moderate affinity, which is contrary to 40 as it shares weak affinity. These results exhibited that the combining capacity in the following order of $\mathbf{4 l}>$ ningnanmycin $>\mathbf{4 d}>\mathbf{4 0}$ is consistent with the trends of the screening of antiviral activities. Based on the experimental results it can be predicted that compound $\mathbf{4 1}$ may interact with TMV CP. As depicted in Fig. 4 and Table 3, the bioactivity was mainly determined by the electrostatic interactions, and the activity could have been enhanced by the presence of aromatic ring which is rich in electrons for absorption. For example, when $\mathrm{R}$ was substituted with a 4-F-Ph group, the corresponding compound (4l) exhibited a stronger combining capacity, with $K_{\mathrm{d}}$ values of $0.275 \pm$ $0.160 \mu \mathrm{mol} \mathrm{L}^{-1}$, as compared to that of compounds $4 \mathrm{~d}(81.744 \pm$ $\left.22.310 \mu \mathrm{mol} \mathrm{L}^{-1}\right)$ and $40\left(245.285 \pm 63.860 \mu \mathrm{mol} \mathrm{L}^{-1}\right)$, which was substituted with a 2,4 -di-OMe-Ph or 4 -methylthiazole.

\subsection{Molecular docking of 41 and TMV-CP}

Molecular docking studies (Fig. 5) for 41 with TMV-CP (PDB code:1EI7) ${ }^{44}$ have shown that the compound was wellembedded between the two subunits of TMV-CP (including residues of GLU131, LYS268, GLN257, ALA74, ASN73, PHE12 and TYR139). Previous reports have demonstrated that these residues play important roles in the self-assembly of TMV particles. ${ }^{\mathbf{4 4 , 4 5}}$ Some hydrophobic aromatic components and clusters such as PHE12, LYS268 and TRY139, play a key role in the continuous hydrophobic interactions within each ring of this assembly. ${ }^{45}$ In addition, there are strong interactions between GLU131, ASN73, ALA74 and GLN257 and other subunits of TMV-CP. ${ }^{44}$ Moreover, there are also notable effects of hydrogen bonding, $\pi$-sulfur, $\pi$-alkyl, and alkyl between the molecules and the above residues in TMV-CP as depicted in Fig. 5. For instance, ASN73 showed strong hydrogen bond with $41(2.35 \AA)$, and triazine demonstrates $\pi$-alkyl interaction with the residue VAL-74. There was also $\pi$-alkyl interaction between the phenyl group and the residue VAL-74. These interactions between molecules and TMV-CP are likely to weaken the interaction of two subunits of TMV-CP, thereby preventing the selfassembly of TMV particle, as well as the binding capability with TMV-CP. The results of molecular docking studies were consistent with the experimental results (protection and inactivation activities) and support that the chalcone derivatives may be potential lead structures for developing novel anti-TMV agents.

\subsection{Antibacterial activities}

The antibacterial activities of the title compounds against Xoo, $R$. solanacearum and Xac were evaluated at $100 \mu \mathrm{g} \mathrm{mL}{ }^{-1}$ using a turbidimeter., ${ }^{\mathbf{2 , 9 , 4 6}}$ The commercial bactericide, bismerthiazol and thiadiazole-copper were tested as a control under the same conditions, and the obtained results are summarized in Table 4 . It can be observed from this table that most of the target compounds exhibited considerable antibacterial effects against $X o o, R$. solanacearum and Xac. For instance, compounds 4c, 4d, $\mathbf{4 g}$ and $4 \mathbf{n}$ presented antibacterial activities against $X o o$ at 100 $\mu \mathrm{g} \mathrm{mL} \mathrm{m}^{-1}$, with the inhibition rates of $62.9 \%, 60.5 \%, 61.8 \%$ and $69.0 \%$, respectively, which are better than that of bismerthiazol (56.1\%) and thiadiazole-copper (32.7\%). The inhibition rates of compounds $\mathbf{4 c}, \mathbf{4 d}, \mathbf{4 g}$ and $\mathbf{4 n}$ against $X o o$ at $50 \mu \mathrm{g} \mathrm{mL}{ }^{-1}$ were $44.9 \%, 39.9 \%, 44.5 \%$ and $42.3 \%$, respectively, which were better than that of thiadiazole-copper $(27.2 \%)$ and similar to bismerthiazol (49.3\%). Moreover, compounds 4a, 4j, 4l, 4n, 4r, 4s and 4w presented excellent antibacterial activities against $R$. solanacearum at $100 \mu \mathrm{g} \mathrm{mL} \mathrm{m}^{-1}$, with the inhibition rates of $93.7 \%$, $87.9 \%, 88.6 \%, 99.9 \%, 96.7 \%, 85.1 \%$ and $94.2 \%$, respectively, which are higher as compared to bismerthiazol $(52.1 \%)$ and thiadiazole-copper (80.2\%). Compounds $4 \mathbf{a}, \mathbf{4 j}, \mathbf{4 l}, \mathbf{4 n}, \mathbf{4 r}, \mathbf{4 s}$ and 4w revealed excellent antibacterial activities against $R$. solanacearum at $50 \mu \mathrm{g} \mathrm{mL} \mathrm{mL}^{-1}$ with the inhibition rates of $74.2 \%$,

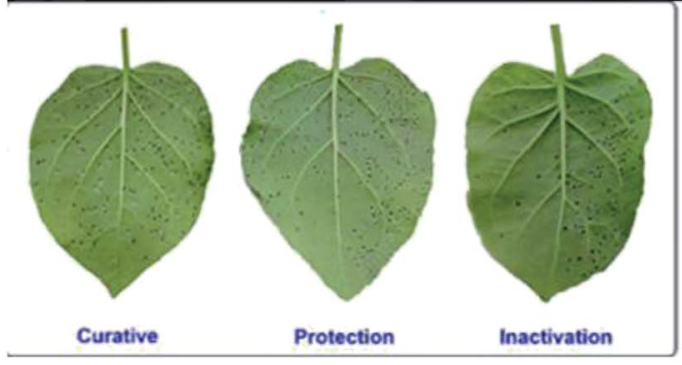

Ningnanmycin

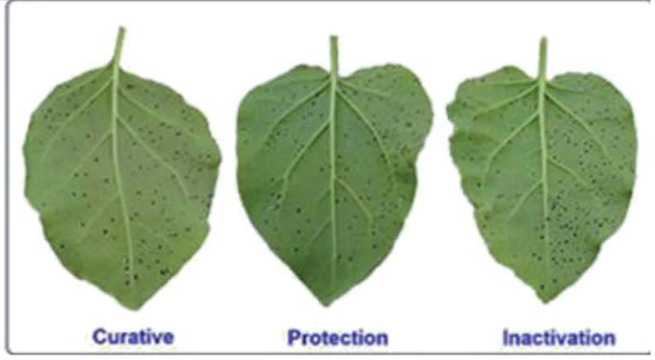

41

Fig. 3 Tobacco leaf morphology effects of the ningnanmycin and $4 \mathrm{l}$ against TMV in vivo. (Right leaf: not treated with compound; left leaf: smeared with compound). 

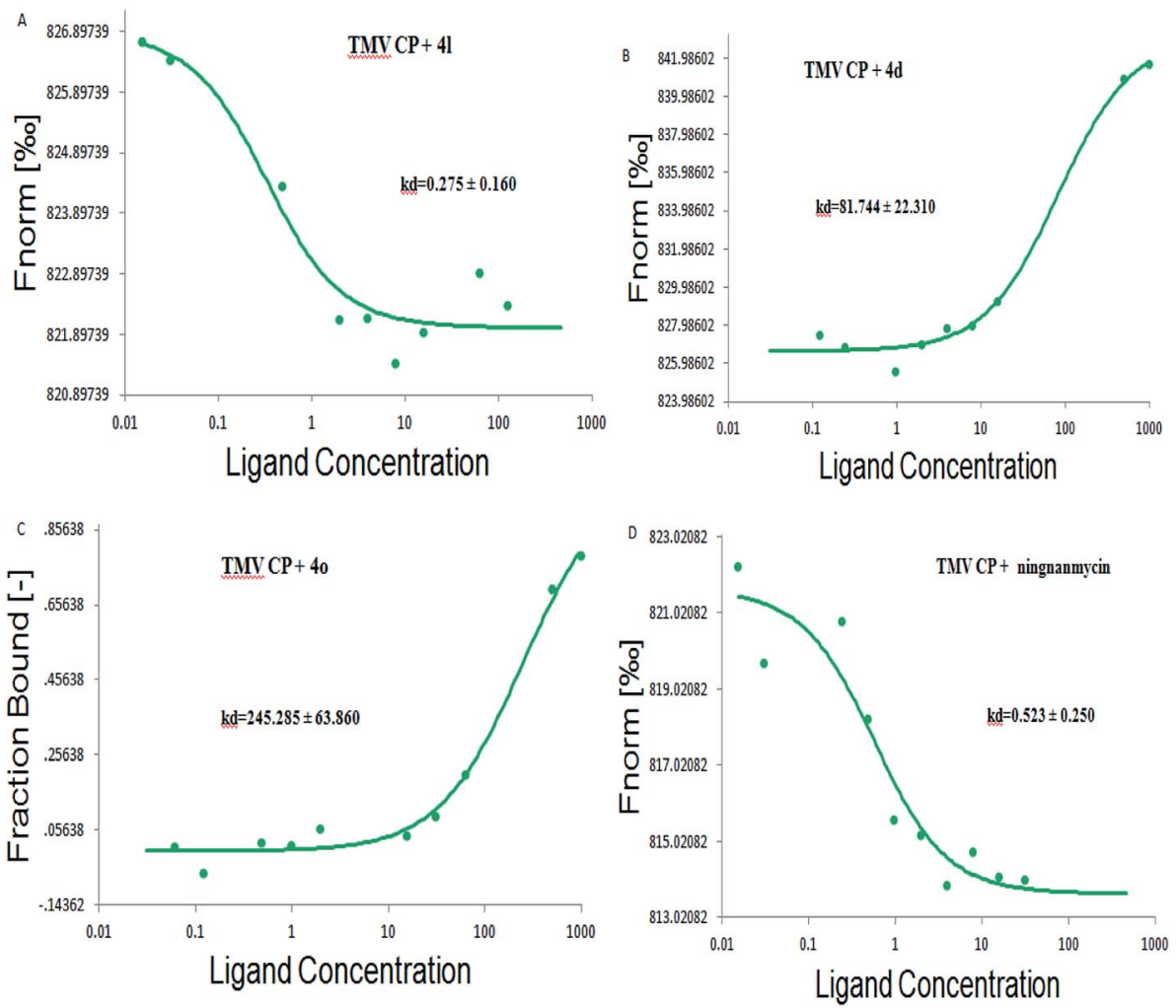

Fig. 4 Microscale thermophoresis (MST) of $4 \mathrm{l}(\mathrm{A})$; 4d (B); 4o (C) and ningnanmycin (D).

Table 3 The dissociation constant of $4 \mathrm{l}, 4 \mathrm{~d}, 40$ and ningnanmycin with TMV-coat protein (TMV-CP)

Compd.

\section{1}

4d

40

Ningnanmycin
$K_{\mathrm{d}}\left(\mu \mathrm{mol} \mathrm{L}{ }^{-1}\right)$

$0.275 \pm 0.16$

$81.744 \pm 22.31$

$245.285 \pm 63.86$

$0.523 \pm 0.25$
$70.0 \%, 82.9 \%, 74.8 \%, 71.1 \%, 80.3 \%$ and $87.0 \%$, respectively. These rates were also higher compared to bismerthiazol (44.2\%) and thiadiazole-copper (48.3\%). In addition, compounds $4 \mathbf{4 a}, \mathbf{4 c}$, 4d, 4e, 4j, 4m and $\mathbf{4 n}$ at 100 and $50 \mu \mathrm{g} \mathrm{mL}{ }^{-1}$, exhibited better antibacterial activities against Xac than bismerthiazol (70.5\% and $33.6 \%$ ) and thiodiazole-copper (75.9\% and $29.5 \%$ ), with the values of $81.1 \%$ and $66.5 \%, 81.2 \%$ and $60.9 \%, 83.3 \%$ and $60.6 \%, 93.1 \%$ and $40.0 \%, 96.8 \%$ and $48.6 \%, 88.0 \%$ and $62.7 \%$ and $87.7 \%$ and $79.4 \%$, respectively.

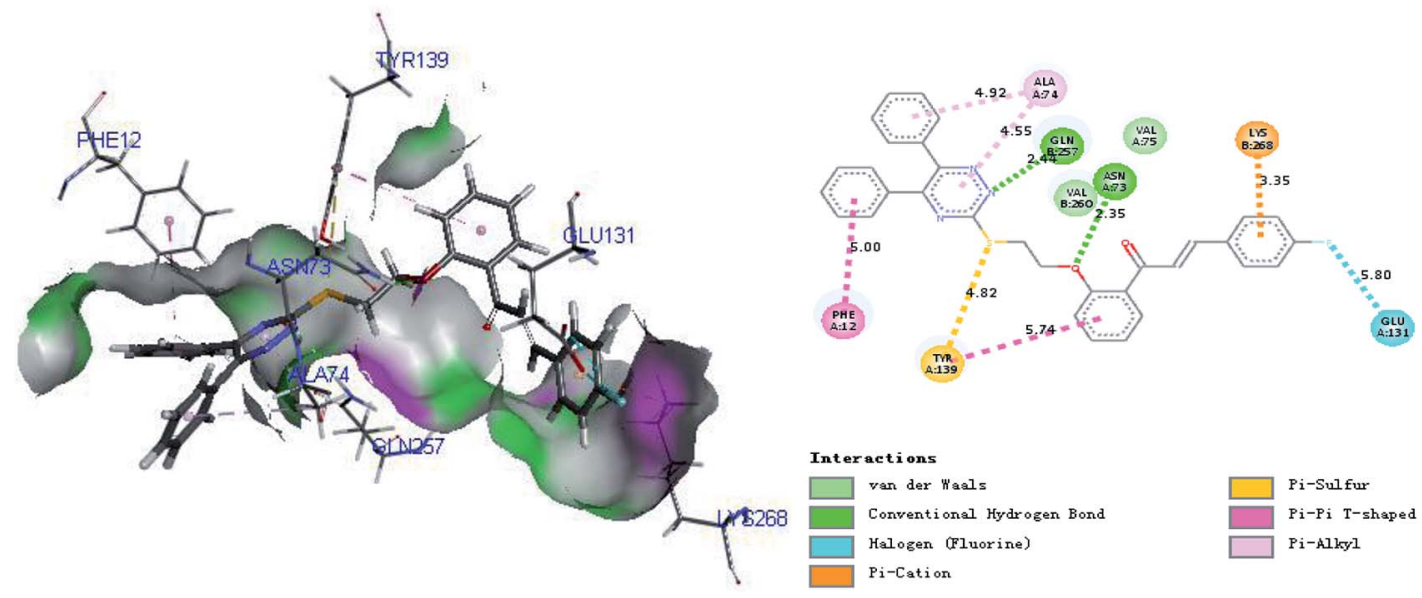

Fig. 5 The binding mode of compound $4 \mathrm{l}$ docked with TMV-CP. 
Table 4 Inhibition effect of the title compounds against Xoo, R. solanacearum and $X a c^{b}$

\begin{tabular}{|c|c|c|c|c|c|c|}
\hline Compd. & \multicolumn{6}{|c|}{ Inhibition (\%) } \\
\hline $4 a$ & $35.4 \pm 5.4$ & $32.7 \pm 8.2$ & $93.7 \pm 4.5$ & $74.2 \pm 0.2$ & $81.1 \pm 3.5$ & $66.5 \pm 1.7$ \\
\hline 4d & $60.5 \pm 2.4$ & $39.9 \pm 2.5$ & $78.5 \pm 3.0$ & $77.7 \pm 1.6$ & $83.3 \pm 5.4$ & $60.6 \pm 1.7$ \\
\hline $4 e$ & $25.4 \pm 5.4$ & $22.7 \pm 8.2$ & $74.7 \pm 0.5$ & $53.8 \pm 3.4$ & $93.1 \pm 9.0$ & $40.0 \pm 3.0$ \\
\hline 4f & $27.9 \pm 2.0$ & $24.7 \pm 2.7$ & $70.3 \pm 1.6$ & $57.6 \pm 6.6$ & $56.4 \pm 2.4$ & $51.3 \pm 4.1$ \\
\hline $4 \mathrm{~g}$ & $61.8 \pm 5.7$ & $44.5 \pm 3.6$ & $83.5 \pm 4.5$ & $81.8 \pm 1.8$ & $63.0 \pm 1.2$ & $49.3 \pm 3.7$ \\
\hline $4 h$ & $18.8 \pm 3.5$ & $24.0 \pm 5.6$ & $71.9 \pm 2.1$ & $70.3 \pm 3.2$ & $75.4 \pm 3.3$ & $48.4 \pm 0.6$ \\
\hline $4 i$ & $18.0 \pm 2.6$ & $11.2 \pm 3.0$ & $83.7 \pm 2.8$ & $79.8 \pm 2.0$ & $53.0 \pm 1.0$ & $33.2 \pm 9.3$ \\
\hline 40 & $17.2 \pm 4.6$ & $15.1 \pm 4.6$ & $72.5 \pm 2.4$ & $68.7 \pm 1.8$ & $39.3 \pm 6.0$ & $27.7 \pm 6.0$ \\
\hline $4 p$ & $15.6 \pm 4.2$ & $11.1 \pm 1.2$ & $63.9 \pm 8.3$ & $58.0 \pm 14.3$ & $64.5 \pm 1.1$ & $50.2 \pm 10.5$ \\
\hline $4 q$ & $26.5 \pm 1.0$ & $25.2 \pm 2.1$ & $80.3 \pm 0.6$ & $70.9 \pm 2.8$ & $39.8 \pm 1.8$ & $29.1 \pm 3.1$ \\
\hline $4 r$ & $35.4 \pm 3.3$ & $28.8 \pm 4.3$ & $96.7 \pm 2.7$ & $71.1 \pm 1.5$ & $41.8 \pm 2.6$ & $40.9 \pm 1.4$ \\
\hline $4 \mathrm{~s}$ & $19.2 \pm 4.6$ & $13.2 \pm 4.6$ & $85.1 \pm 3.6$ & $80.3 \pm 3.4$ & $65.1 \pm 4.1$ & $45.8 \pm 9.1$ \\
\hline $4 t$ & $12.2 \pm 0.8$ & $11.6 \pm 3.6$ & $75.8 \pm 3.0$ & $61.7 \pm 3.2$ & $63.9 \pm 1.2$ & $51.7 \pm 2.7$ \\
\hline $4 w$ & $42.1 \pm 6.2$ & $31.0 \pm 6.0$ & $94.2 \pm 2.6$ & $87.0 \pm 3.5$ & $70.7 \pm 2.1$ & $65.7 \pm 4.9$ \\
\hline $\mathrm{BT}^{a}$ & $56.1 \pm 7.3$ & $49.3 \pm 5.4$ & $52.1 \pm 3.4$ & $44.2 \pm 3.9$ & $70.5 \pm 1.5$ & $33.6 \pm 1.7$ \\
\hline $\mathrm{TC}^{a}$ & $37.2 \pm 0.9$ & $27.2 \pm 3.2$ & $80.2 \pm 4.0$ & $48.3 \pm 4.8$ & $75.9 \pm 1.5$ & $29.5 \pm 4.3$ \\
\hline
\end{tabular}

${ }^{a}$ BT: bismerthiazol; TC: thiadiazole-copper; average of three replicates. ${ }^{b}$ A commercial agricultural antibacterial agent bismerthiazol and thiadiazole-copper were used for comparison of antibacterial activities.

Based on these preliminary results of bioassays, $\mathrm{EC}_{50}$ values of some of the compounds showed excellent antibacterial activities against Xoo, Xac and $R$. solanacearum as indicated in Table 5. As can be seen from Table 5, compounds $4 \mathbf{a}$ and $\mathbf{4 e}$ exhibited satisfactory in vitro antibacterial activities against $X a c$, with the $\mathrm{EC}_{50}$ values of 53.6 and $67.0 \mu \mathrm{g} \mathrm{mL}^{-1}$, which were higher than that of bismerthiazol (153.7 $\left.\mu \mathrm{g} \mathrm{mL}^{-1}\right)$ and thiodiazole-copper $\left(77.8 \mu \mathrm{g} \mathrm{mL}^{-1}\right)$ (Table 5). Also, compound $\mathbf{4 g}$ was found to exhibit higher antibacterial activity against Xoo $\left(76.7 \mu \mathrm{g} \mathrm{mL}^{-1}\right)$, than bismerthiazol $\left(94.5 \mu \mathrm{g} \mathrm{mL}{ }^{-1}\right)$. On the other hand, as shown in Table 5 , the title compounds $\mathbf{4 a - 4 w}$ exhibited in vitro antibacterial activities against $R$. solanacearum, with the $\mathrm{EC}_{50}$ values of $0.1-93.9 \mu \mathrm{g} \mathrm{mL} \mathrm{m}^{-1}$. The target compounds $\mathbf{4 a}, \mathbf{4 g}, \mathbf{4 j}, \mathbf{4 l}, \mathbf{4 s}, \mathbf{4 t}$ and $\mathbf{4 v}$ showed excellent in vitro antibacterial activities against $R$. solanacearum, with the $\mathrm{EC}_{50}$ values of $0.1,0.1,0.3,0.4,0.2,0.1$ and $2.7 \mu \mathrm{g} \mathrm{mL}^{-1}$, respectively. These values were comparable with thiodiazolecopper $\left(36.1 \mu \mathrm{g} \mathrm{mL} L^{-1}\right)$ and bismerthiazol $\left(49.5 \mu \mathrm{g} \mathrm{mL}^{-1}\right)$ as shown in Table 5 .

\subsection{Structure-activity relationships (SAR) of antibacterial activities}

Table 4 reveals that the antibacterial activities of the title compounds were considerably affected by the structural variations in the chalcone derivatives that contain 1,2,4-triazine moiety. Notably, all the title compounds exhibited better anti $R$. solanacearum and anti Xac activities than their corresponding anti Xoo activities as could be observed from the results presented in Table 4. The antibacterial activities of the title compounds were also affected by the nature or identity of different groups attached to $\mathrm{R}$. For instance, the designated compounds $4 \mathbf{a}\left(\mathrm{R}=-\mathrm{NO}_{2}-\mathrm{Ph}\right), 4 \mathrm{j}(\mathrm{R}=4$-OMe-Ph), $4 \mathbf{l}(\mathrm{R}=4-\mathrm{F}-$ $\mathrm{Ph}), \mathbf{4 n}(\mathrm{R}=N, N$-di-Me-Ph), $\mathbf{4 r}(\mathrm{R}=$ isopropyl-Ph) and $\mathbf{4 w}(\mathrm{R}$ $=4$-methylthiazole) exhibited significant anti $R$. solanacearum effects at $100 \mu \mathrm{g} \mathrm{mL} \mathrm{mL}^{-1}$, with the inhibition rates of $93.7 \%$, $87.9 \%, 88.6 \%, 99.9 \%, 96.7 \%$ and $94.2 \%$, respectively. These compounds were found to be more active compared to other tested compounds. However, when $\mathrm{R}$ was substituted with 4$\mathrm{NO}_{2}$-Ph, 2,4-di-OMe-Ph, phenyl, 4-OMe-Ph, 2-F-Ph and $\mathrm{N}, \mathrm{N}$-di$\mathrm{Me}-\mathrm{Ph}$ groups, the activities of the corresponding compounds 4a, 4d, 4e, 4j, 4m and 4n, against $X a c$ at $100 \mu \mathrm{g} \mathrm{mL}{ }^{-1}$ were $81.1 \%, 83.3 \%, 93.1 \%, 96.8 \%, 88.0 \%$ and $87.7 \%$, respectively, which were higher than that of bismerthiazol $(70.5 \%)$ and thiadiazole-copper (75.9\%).

\subsection{SEM study}

In order to further explore the mechanism of antibacterial action against $R$. solanacearum, scanning electron microscopic (SEM) studies were carried out using the designated compound 4a and the observed SEM micrographs are shown in Fig. 6. It could be noted that the compounds act by causing the bacterial cell membranes to wrinkle. Wrinkling of the cell membranes 
Table $5 \mathrm{EC}_{50}$ values of some title compounds against Xoo, Xac and R. solanacearum ${ }^{b}$

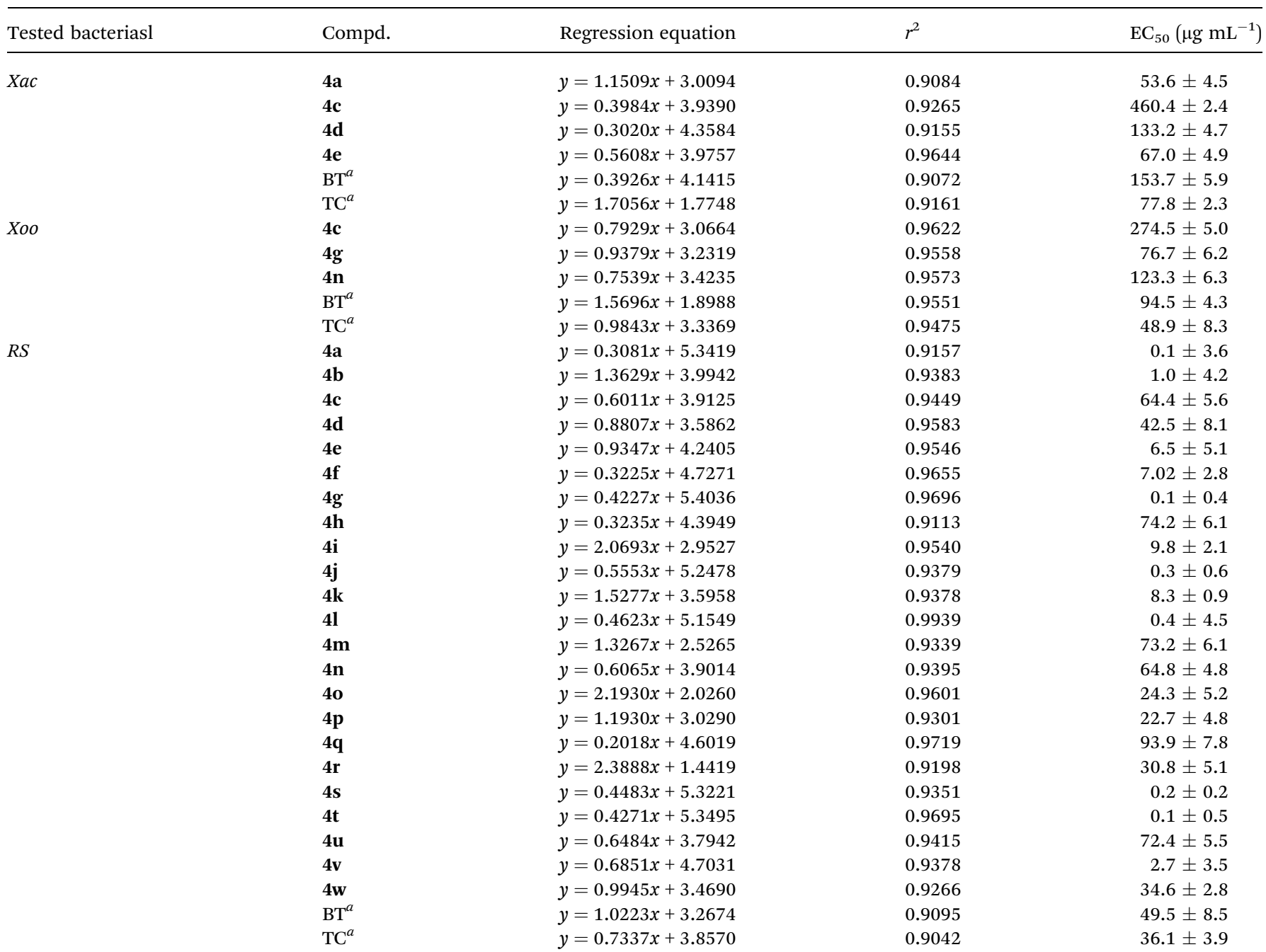

${ }^{a}$ BT: bismerthiazol; TC: thiadiazole-copper. ${ }^{b}$ A commercial agricultural antibacterial agent bismerthiazol and thiadiazole-copper were used for comparison of antibacterial activities.

became more obvious with an increase in the concentration of compound 4a. For instance, when the concentration was 12.5 $\mu \mathrm{g} \mathrm{mL}{ }^{-1}$, the cell membrane began to wrinkle (Fig. 6B). Whereas, a further increase in the concentration to $50 \mu \mathrm{g} \mathrm{mL}^{-1}$, it results in the development of folds in the cell membrane
(Fig. 6C). In contrast, without any treatment with compound $\mathbf{4 a}$, the bacterial cells were smooth and the cell membrane was intact (Fig. 6A). The results from SEM provide clear evidence that the compound 4a exhibited antibacterial effects on the cell, and this effect might eventually results in cell death.

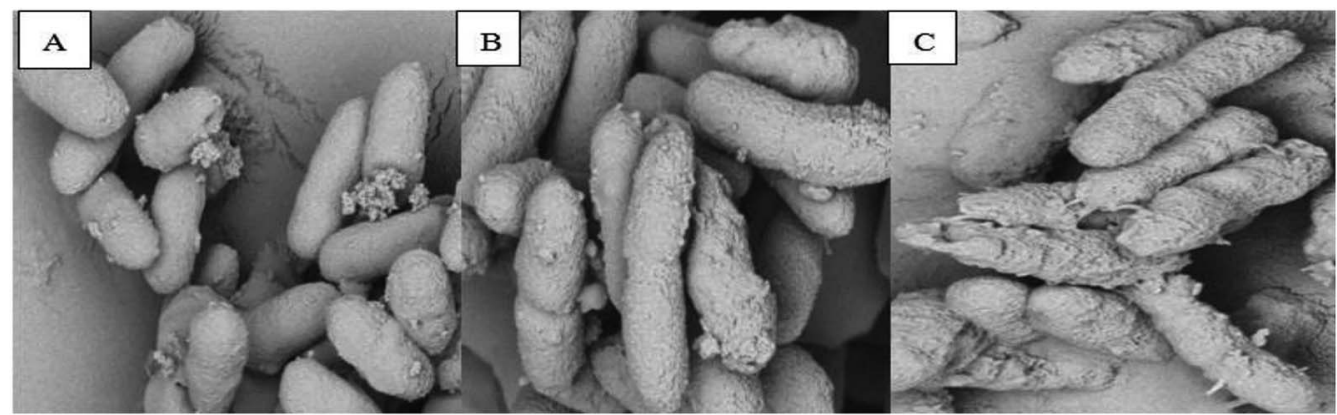

Fig. 6 SEM images for $R$. solanacearum after incubated in different concentration of compound 4 a (A) $0 \mathrm{mg} \mathrm{mL}^{-1}$, (B) $12.5 \mathrm{mg} \mathrm{mL}^{-1}$, and (C) $50 \mathrm{mg} \mathrm{mL}^{-1}$. Scale bar for (A, B and C) are $2 \mu \mathrm{m}$. 


\section{Conclusions}

With the aim to develop novel, highly-efficient and environmentally benign agrochemicals, 1,2,4-triazine scaffold was introduced into chalcone structure to synthesize chalcone derivatives, and also their in vivo antibacterial and antiviral activities were evaluated. The obtained bioassay results revealed that some of the title compounds exhibited excellent antibacterial and antiviral activities and notably they were better than the commercial agents. Compound $\mathbf{4 l}$ exhibited significant curative and protective activities against tobacco mosaic virus (TMV), with the $\mathrm{EC}_{50}$ values of $10.9 \mu \mathrm{g} \mathrm{mL}^{-1}$ and $79.4 \mu \mathrm{g} \mathrm{mL}^{-1}$, which was better than that of ningnanmycin $\left(81.4 \mu \mathrm{g} \mathrm{mL}^{-1}\right.$ and $82.2 \mu \mathrm{g} \mathrm{mL}^{-1}$ ). Microscale thermophoresis (MST) showed that the binding of compound $\mathbf{4 l}$ to coat protein (TMV-CP) yielded $K_{\mathrm{d}}$ values of $0.275 \pm 0.160 \mu \mathrm{mol} \mathrm{L}{ }^{-1}$, which was better than that of ningnanmycin $\left(0.523 \pm 0.250 \mu \mathrm{mol} \mathrm{L}{ }^{-1}\right)$. Molecular docking studies for 41 with TMV-CP (PDB code: 1EI7) showed that the compound was embedded well in the pocket between the two subunits of TMV-CP. Compounds $4 \mathbf{a}, 4 \mathbf{g}, 4 \mathbf{j}, 4 \mathbf{s}, 4 \mathbf{l}$ and $4 \mathbf{t}$ demonstrated excellent antibacterial activities against $R$. solanacearum, with the $\mathrm{EC}_{50}$ values of $0.1,0.1,0.3,0.46$ and $0.1 \mu \mathrm{g}$ $\mathrm{mL}^{-1}$, which were better than that of thiodiazole-copper (36.1 $\mu \mathrm{g} \mathrm{mL}^{-1}$ ) and bismerthiazol (49.5 $\left.\mu \mathrm{g} \mathrm{mL}^{-1}\right)$. The observed antibacterial activity could be due to folding and deformation of the bacterial cell membrane by the addition of compound as observed using SEM. All these results support that the chalcone derivatives containing 1,2,4-triazine moiety possess antibacterial effects, and thus could be further studied as potential alternative templates in the search for novel antiviral and antibacterial agents.

\section{Conflicts of interest}

The authors declare that they have no competing interests.

\section{Acknowledgements}

The authors gratefully acknowledge the financial support of the National Key Research and Development Program of China (No. 2017YFD0200506) and Science and Technology Project of Guizhou Province (No. 20185781, 20171028).

\section{References}

1 L. F. Zou, L. I. Yu-Rong and G. Y. Chen, Agric. Sci. China, 2011, 10, 1139-1150.

2 P. Li, P. Tian, Y. Chen, Y. Z. Chen, S. Yang and B. A. Song, Pest Manage. Sci., 2017, 11, 106.

3 P. Y. Wang, W. B. Shao, H. T. Xue, B. A. Song and S. Yang, Res. Chem. Intermed., 2017, 43, 6115-6130.

4 G. Han, L. Chen and Q. Wang, J. Agric. Food Chem., 2018, 66, 780-788.

5 A. Hazra, S. Mondal and A. Maity, Eur. J. Med. Chem., 2011, 46, 2132-2140.

6 H. Khalilullah and M. J. Ahsan, Mini-Rev. Med. Chem., 2012, 12, 789 .
7 P. Y. Wang, L. Zhou, J. Zhou, Z. B. Wu, W. Xue, B. A. Song and S. Yang, Bioorg. Med. Chem. Lett., 2016, 26, 1214-1217.

8 X. Wang, P. Li, Z. Li, J. Yin, M. He, W. Xue, Z. Chen and B. A. Song, J. Agric. Food Chem., 2013, 61, 9575-9582.

9 X. M. Zhong, X. B. Wang, L. J. Chen and W. Xue, Chem. Cent. J., 2017, 11, 106.

10 Y. Lu and X. H. Gan, Molecules, 2017, 22, 658.

11 R. Schobert, B. Biersack and A. Dietrich, J. Med. Chem., 2009, 52, 241-246.

12 S. Vogel, M. Barbic and J. Guido, Eur. J. Med. Chem., 2010, 45, 2206-2213.

13 V. Tomar and G. Bhattacharjee, Eur. J. Med. Chem., 2010, 45, 745-751.

14 J. C. Aponte, D. Castillo and Y. Estevez, Bioorg. Med. Chem. Lett., 2010, 20, 100-103.

15 B. T. Yin, C. Y. Yan and X. M. Peng, Eur. J. Med. Chem., 2014, 71, 148-159.

16 Z. Nowakowska, Eur. J. Med. Chem., 2007, 42, 125-137.

17 Y. Zuo, Y. Yu and S. Wang, Eur. J. Med. Chem., 2014, 50, 393404.

18 Y. J. Wang, D. G. Zhou and F. C. He, Chin. Chem. Lett., 2018, 29, 127-130.

19 S. Kuthyala, G. K. Nagaraja and S. Sheik, J. Mol. Struct., 2018, 1177, 381-390.

20 K. Sharanabasappa, J. Megha and B. Prakash, J. Mol. Struct., 2018, 1173, 142-147.

21 S. Gurjaspreet, A. Aanchal, K. Pooja and K. M. Indresh, Bioorg. Med. Chem., 2018, 27, 188-195.

22 J. E. Kang, J. K. Cho, M. J. Curtis-Long, H. W. Ryu and J. H. Kim, Molecules, 2013, 18, 140-153.

23 A. O. Oyedapo, V. O. Mankanju, C. O. Adewunmi, E. O. Iwalewa and T. K. Adenowo, Afr. J. Tradit., Complementary Altern. Med., 2004, 1, 55-62.

24 J. C. Aponte, M. Verastegui, E. Malaga, M. Zimic, M. Quiliano, A. J. Vaisberg, R. H. Gilman and G. B. Hammond, J. Med. Chem., 2008, 51, 6230-6234.

25 V. S. Verma, Zentralbl. Bakteriol., Parasitenkd., Infektionskrankh. Hyg., Abt. 2, Naturwiss.: Allg., Landwirtsch. Tech. Mikrobiol., 1973, 128, 467-472.

26 Z. H. Wan, D. Y. Hu and P. Li, Molecules, 2015, 20, 1186111874.

27 X. H. Gan, D. Y. Hu and Y. Wang, J. Agric. Food Chem., 2017, 65, 4367-4377.

28 H. Irannejad, M. Amini, F. Khodagholi, N. Ansari, S. K. Tusi, M. Sharifzadeh and A. Shafiee, Bioorg. Med. Chem., 2010, 18, 4224-4230.

29 G. Wang, Z. Peng, J. Wang, X. Li and J. Li, Eur. J. Med. Chem., 2017, 125, 423-429.

30 E. Plebanek, F. Chevrier, V. Roy, T. Garenne, F. Lecaille, D. Warszycki, A. J. Bojarski, G. Lalmanach and L. A. Agrofoglio, Eur. J. Med. Chem., 2016, 121, 12-20.

31 P. Singla, V. Luxami and K. Paul, Eur. J. Med. Chem., 2016, 117, 59-69.

32 R. S. Tamboli, R. Giridhar and H. P. Gandhi, J. Enzyme Inhib. Med. Chem., 2015, 5, 1475-6366.

33 M. Khoshneviszadeh, O. Shahraki and M. Khoshneviszadeh, J. Enzyme Inhib. Med. Chem., 2016, 31, 1-10. 
34 D. J. Fu, J. Song and Y. H. Hou, Eur. J. Med. Chem., 2017, 138, 1076-1088.

35 S. Konno, T. Kokubo and M. Amano, Yakugaku Zasshi, 1992, 112, 729-741.

36 A. Monge, J. Palop and C. Ramirez, Eur. J. Med. Chem., 1991, 26, 179-188.

37 M. O'Rourke and S. A. Lang-Jr, Bioorg. Med. Chem. Lett., 1977, 20, 6024-6029.

38 R. S. Tamboli, R. Giridhar and H. P. Gandhi, J. Enzyme Inhib. Med. Chem., 2015, 31, 704-713.

39 P. Li, L. Shi and M. N. Gao, Bioorg. Med. Chem. Lett., 2015, 25, 481-484.
40 Y. Jin, B. A. Song, D. Y. Hu, X. Y. Li, P. S. Bhadury, Z. C. Wang and S. Yang, Chem. Cent. J., 2011, 5, 21.

41 G. Wang and Z. Peng, Bioorg. Chem., 2018, 78, 195-200.

42 C. J. Wienken, P. Baaske and U. Rothbauer, Nat. Commun., 2011, 1, 100.

43 B. Bhyravbhatla, S. J. Watowich and D. L. Caspar, Biophys. J., 1998, 74, 604-615.

44 Y. Y. Wang, F. Z. Xu and Y. Y. Zhan, Bioorg. Med. Chem. Lett., 2018, 28, 2979-2984.

45 A. C. Bloomer, J. N. Champness and G. Bricogne, Nature, 1978, 276, 362-368.

46 X. B. Wang, Z. J. Ren, M. Q. Wang and M. Chen, Chem. Cent. J., 2018, 12, 83. 